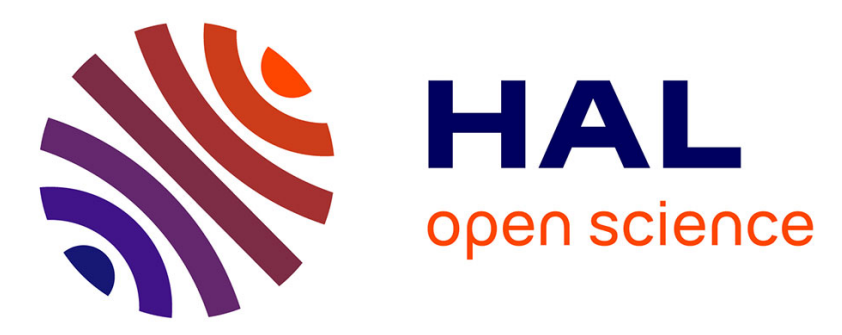

\title{
Long-term decline despite conservation efforts questions Eurasian Stone-curlew population viability in intensive farmlands
}

Elie Gaget, Rémi Fay, Steve Augiron, Alexandre Villers, Vincent Bretagnolle

\section{- To cite this version:}

Elie Gaget, Rémi Fay, Steve Augiron, Alexandre Villers, Vincent Bretagnolle. Long-term decline despite conservation efforts questions Eurasian Stone-curlew population viability in intensive farmlands. Ibis, 2019, 161 (2), pp.359-371. 10.1111/ibi.12646 . hal-02013687

\section{HAL Id: hal-02013687 \\ https://hal.science/hal-02013687}

Submitted on 12 Jul 2019

HAL is a multi-disciplinary open access archive for the deposit and dissemination of scientific research documents, whether they are published or not. The documents may come from teaching and research institutions in France or abroad, or from public or private research centers.
L'archive ouverte pluridisciplinaire HAL, est destinée au dépôt et à la diffusion de documents scientifiques de niveau recherche, publiés ou non, émanant des établissements d'enseignement et de recherche français ou étrangers, des laboratoires publics ou privés. 
DR. ELIE GAGET (Orcid ID : 0000-0003-3462-9686)

DR. ALEXANDRE VILLERS (Orcid ID : 0000-0003-3050-4106)

Long-term decline despite conservation efforts questions Eurasian Stone-curlew population viability in intensive farmlands

\author{
ELIE GAGET, ${ }^{1,2,3^{*}}$ REMI FAY, ${ }^{1}$ STEVE AUGIRON, ${ }^{1,4}$ ALEXANDRE VILLERS ${ }^{1,5}$ \& VINCENT \\ BRETAGNOLLE ${ }^{1,6}$
}

${ }^{1}$ Centre d'Etudes Biologiques de Chizé, UMR 7372, CNRS \& Université de La Rochelle, 79360, Beauvoir sur Niort, France

${ }^{2}$ Tour du Valat, Institut de recherche pour la conservation des zones humides Méditerranéennes, 13200, Le Sambuc, Arles, France

${ }^{3}$ CESCO, UMR 7204 UPMC-CNRS-MNHN, 55 rue Buffon, 75005 Paris, France

${ }^{4}$ GeolinkX, P-A Côte Rousse, 180 rue du Genevois, 73000 Chambéry, France

${ }^{5}$ INRA, Biostatistics \& Spatial Processes (BioSP), Domaine Saint-Paul, Site Agroparc, 84914 Avignon

${ }^{6}$ LTSER «Zone Atelier Plaine \& Val de Sèvre », CNRS, 79360, Beauvoir sur Niort, France elie.gaget@gmail.com; steve.augiron@geolinkx.com; fay.remi@gmail.com; villers.alexandre@gmail.com; breta@cebc.cnrs.fr 
Corresponding author.

Email: elie.gaget@gmail.com

Agricultural intensification over the past decades has led to a generalised decline in farmland biodiversity. Farmland birds are particularly exposed to rapid changes in habitat and reduced food resources or availability. Understanding how farmland specialists can be preserved and their populations enhanced are major challenges for this century. Based on a long-term (19year) study of a Eurasian Stone-curlew Burhinus oedicnemus population, we estimated the demographic parameters, including clutch size, egg volume, hatching success, survival rate and apparent population size. Demographic rates found for this French population were, on average, comparable to those found elsewhere in Europe. However, all demographic parameters showed negative trends, including a dramatic decline in the local population (26\% decline over 14 years) and a 10\% decline in adult survival rate over 11 years. Such a long-term decline, despite on-going conservation efforts, questions the overall sustainability of arable Stone-curlew populations. We infer some of the possible causes of this decline, in particular food-shortage, and discuss how this pattern could be reversed through conservation measures applicable at very large spatial scales.

Keywords: Burhinus oedicnemus, breeding, demographic rate, farmland birds, population dynamics, population monitoring, protection status.

Agricultural expansion over the last 10000 years has created a complex mosaic of landscapes which replaced primeval forests and steppe habitats (Kaplan et al. 2009). Extensive farming allowed the colonization of these new habitats by numerous species of birds, usually of steppe origin (O'Connor \& Shrubb 1986). However, over the past century, intensive agriculture has replaced traditional farming, a trend that has been accelerated by the Common Agricultural Policy (CAP) in Western Europe since 1962. CAP-induced changes in agricultural practices are a major cause of farmland biodiversity loss, especially birds 
(Krebs et al. 1999, Donald et al. 2001). Farmland specialist birds have been extensively studied in order to understand the multifactorial causes of decline linked to intensive farming practices (Aebischer \& Ewald 2012, Kentie et al. 2013, Chiron et al. 2014, Barré et al. 2018). However, the breeding ecology of several farmland birds, including some threatened species, and the detailed mechanisms by which they are affected by intensive farming practices, still have to be elucidated in many cases (Fuller et al. 1995, Chamberlain et al. 2000, Heldbjerg et al. 2017, Stanton et al. 2018).

The Eurasian Stone-curlew Burhinus oedicnemus (Charadriformes, Burhinidae; henceforth Stone-curlew) is a steppic Palearctic bird occurring in European farmlands and pseudo-steppes (Vaughan \& Vaughan-Jennings 2005). The species suffered a rapid and important population decline over the second half of the last century (Cramp \& Simmons 1983). However, despite the scarcity and imprecision of national trend data, its European conservation status has remained under the 'least concern' category, with an estimated 53400 - 88200 pairs in the EU (BirdLife International 2017). Indeed, the population trend is unknown for $46 \%$ of European countries, shows positive trends for only $14 \%$, is stable or fluctuating for $21 \%$, and is negative for $18 \%$ (BirdLife International, 2017). Apart from countries where the species is highly localized (e.g. in the UK), trends should probably be best considered as tentative. A decrease in geographical range and breeding population was reported in France over the second half of the $20^{\text {th }}$ century (Yeatman-Berthelot \& Jarry 1994), with an estimated breeding population of 5000-9000 pairs between 1980 and 1993 (Malvaud 1996), with most recent estimates for the French population size of $c$. $19000-28000$ breeding pairs (Issa \& Muller 2015). In the UK, the situation in the eighties was almost desperate, but over the last three decades, owing to a major conservation effort of the RSPB (Evans \& Green 2007), the population reached c. 400 breeding pairs (Eaton et al. 2011).

Stone-curlew population monitoring data are scarce because there are very few longterm field studies that may provide accurate trends, partly because of the elusive behaviour, shyness and excellent camouflage of the species. In addition, Stone-curlew breeding habitat choice is surprisingly flexible: any kind of habitat with drained soils, low vegetation height and 
density, and stones on the ground to optimize anti-predation strategies for this cryptic species, seems to fulfil its habitat requirements (Green et al. 2000). Breeding habitat includes heathlands, semi-natural grasslands, pseudo-steppes, gravel riverbeds, vineyards, orchards, spring-sown crops and brownfields (Vaughan \& Vaughan-Jennings 2005). Conservation success in the UK relied to a large extent on detailed breeding biology and habitat selection studies (Gibbons et al. 1996) which helped shape Agri-Environmental Scheme (AES) implementation (Grice et al. 2007). The latter mainly consisted of nesting plots in an uncultivated area within spring-sown crops of 1-2 ha, away from field boundaries and near pastureland (Evans \& Green 2007). However, implementing this AES elsewhere in Europe requires extended knowledge of the breeding biology of the species, either in arable crops or in more natural steppic or pseudo-steppe habitats.

France, with $21 \%$ of the European population, represents the second largest European breeding population after Spain (BirdLife International 2017). In France, farmland landscapes are the major breeding habitat with over $60 \%$ of breeding pairs being located in arable crops of the central-western region (Malvaud 1996, Issa \& Muller 2015). In such habitat, however, the species is threatened by nest destruction though agricultural work (Berg et al. 2002, Whittingham \& Evans 2004), and chick survival as well as adult fitness are potentially threatened by a decrease in food resources which is known to negatively affect farmland specialists (Donald et al. 2001). The aim of this study was to assess the status and trends (over 19 years) of demographic parameters of a Stone-curlew population breeding in an intensive farmland landscape and benefiting indirectly from agri-environmental conservation measures.

\section{METHODS}

\section{Study area and conservation measures}

The Long Term Social-Ecological Research site (LTSER) 'Zone Atelier Plaine \& Val de Sèvre' (http://www.za.plainevalsevre.cnrs.fr/, Bretagnolle et al. 2018) is located within an 
intensively managed farmland area in the Poitou-Charentes Region, Deux-Sèvres district, central-western France (Fig. 1). The site covers $450 \mathrm{~km}^{2}$ of farmland, where crops are dominated by winter annuals (cereals c. $40 \%$ and rapeseed, c. $15 \%$ of the arable surface), followed by spring crops (sunflower 15\%, maize 10\%), and perennial covers $(10 \%$; Bretagnolle et al. 2018). The plain lies upon a Jurassic sedimentary basin, with well-drained and poor soil, typical of a rendzina (INRA 1998).

Half of the LTSER was designated as a Special Protected Area (SPA Natura2000, FR5412007, $207.6 \mathrm{~km}^{2}$ ) in 2004 due to the presence of 17 species listed in Annex I of the Birds Directive. Some Agri-Environmental Schemes have been implemented on the LTSER since 1999, but since 2004, AES have been implemented more strongly within the framework of CAP (Bretagnolle et al. 2011, Berthet et al. 2012). AES have been mainly targeted toward the conservation of Little Bustards Tetrax tetrax, and consist of increasing grassland cover and fodder crops, decreasing mowing frequency in alfalfa and permanent grasslands from May to August in order to limit nest destruction and the killing of incubating females, and banning pesticides to increase food resources for the chicks (Bretagnolle et al. 2011). Up to 10000 ha of contracts have been established (Bretagnolle et al. 2011, Caro et al. 2016). These measures have increased the overall amount of preserved nesting habitat as well as food resources for many farmlands birds (Bretagnolle et al. 2011, Brodier et al. 2014). Stonecurlews breeding on the LTSER have thus probably benefited from habitats that were on average of higher quality regarding food resources. In addition, since the beginning of monitoring in 1998, the species has benefited from an awareness program toward farmers on a sub-site of 4300 ha (the one where all breeding parameters were collected for this study, see VA sub-site below): nests found following intensive searches were reported to farmers, and nest locations were marked in the field, to avoid destruction during agricultural work. Overall, measures to improve food availability as well as those toward nest protection were expected to maintain, if not increase, reproductive investment (clutch size, egg volume and hatching rate) and hence population size on the VA sub-site. 


\section{Stone-curlew breeding biology}

Breeders were monitored in a delimited sub-site of the LTSER of c. 4300 ha (hereafter, VA), over 19 consecutive years (1998-2016). Each year, from March to June, all fields with favourable vegetation height $(<15 \mathrm{~cm})$ were monitored on a weekly basis (approximately 200-400 fields covering 500-1200 ha). Nests were located from distant vantage points by using a telescope (20x60) and subsequently visited to determine breeding stage precisely. The first visit usually occurred before hatching, when egg biometric measurements allowed the determination of laying and hatching dates with the use of a calibration density curve (Hoyt 1979 and V. Bretagnolle, unpubl. data, SOM1,). Egg weight, length and width were recorded (precision of $0.1 \mathrm{~g}$ and $0.1 \mathrm{~mm}$, Table SOM1). Egg density (mass/volume), which decreases during incubation (Green 1994), was used to estimate egg laying date at a precision of 1.52 days (V. Bretagnolle, unpubl. data, SOM2). Pairs were then re-checked at least once a week to ensure they were still present and incubating. The nests were re-visited if pairs were not observed for two consecutive days, or around the hatching date, to determine the fate of the clutch (hatching, destruction by agricultural work, or desertion/predation). Because it was not possible to determine with certainty if an empty nest had been deserted before eggs were removed by a predator, we used a single category 'desertion/predation'. If at the first nest visit, eggs had already hatched and chicks were still close to the nest, the laying date was retrospectively calculated with reference to the incubation period of 26 days (Vaughan \& Vaughan-Jennings 2005) and the chicks' age (estimated with a precision of 2.6 days with the use of a wing measure calibration curve, V. Bretagnolle, unpubl. Data; SOM3).

For each nest, laying date was thus obtained (for 2-egg clutches, the mean laying date) and expressed in Julian days, starting from the $1^{\text {st }}$ March. Clutches from July to early September ( $<3 \%$ of recorded breeding events) were discarded from the analyses because observation pressure during those months varied over time. Stone-curlews are able to lay replacement clutches after nest failure, as well as true second clutches (Vaughan \& 
Vaughan-Jennings 2005). To estimate the number of breeding attempts per pair, we used a mixture distribution method (log-normal, Bealey et al. 1999) using the observed distribution of the laying dates (R package 'mixdist', Macdonald \& Du 2012). We parameterized the model with the laying date of ringed breeding birds $(n=130)$ and then fitted it on the complete dataset $(n=513)$. This analysis is a combination of the Newton-type method and the estimate mean algorithm (O'Neil 1971). The unconstrained model finds a set of overlapping distributions of laying dates (we used three log-normal distributions, accounting for the possibility of three successive clutches for a given pair) that provides the best fit to grouped data. The quality of the model (comparison between observed data and estimated distributions) was tested with a $X^{2}$ goodness-of-fit test (Macdonald \& Du 2012).

Temporal trends in breeding parameters were then evaluated successively in different models. Trends in laying date, clutch size and egg volume were investigated using a generalized linear model (GLM) either with a Gaussian error distribution (laying date and egg volume) or with a binomial error distribution (clutch size, modelling the probability of a 1-egg clutch or a 2-egg clutch). For the laying date, we tested the temporal trend over years on two subsets: over the breeding season (from March to June) and over the first half of the first breeding attempts, which does not include replacement clutches (from March to the $27^{\text {th }}$ of April). For egg volume and clutch size, we considered the effect of laying date and its interaction with year (Christians 2002). Nest fate was investigated using the Mayfield model based on a maximum likelihood approach. Compared to the initial Mayfield model (Mayfield 1975), no assumption about when the failure occurs is required, and covariates can be easily incorporated (Rotella 2014). We used a multi-state model to include directly the two identified causes of failure i.e. 'destroyed by agricultural work', or 'deserted/predated' (Darrah et al. 2018). We tested if nest survival and causes of failure changed according to year, laying date and clutch size considering linear relationships. Additionally, we tested the effect of the interaction between laying date and year. Nest survival from laying until hatching was calculated by raising the daily survival rate to the power of 26 (i.e. the incubation period) and the corresponding variance was estimated by the delta method (Powell 2007). Nest fate 
model building and parameter estimates were obtained using E-SURGE v.1.8.5 (Choquet et al. 2009a). For all these models investigating the breeding parameters and their temporal trend, we used a model selection inference with AICc criteria. The ability of two models to describe the data was assumed to be identical if the difference in their AICc was $<2$. However, in particular cases where models within the two units of the best model have only one more parameter, the larger model is not necessarily supported or competitive. A closer examination considering the deviance is required to see if the fit is really improved, or rather if the model is 'close' in term of AICc because it adds only one parameter (Burnham and Anderson 2002). In the latter case, we selected the most parsimonious model (i.e. that with the lowest number of parameters).

\section{Trend in apparent population size}

To evaluate the trend in population size, two different methods were used. First, counts were performed every year on four different sub-sites from 2003 to 2016, totalling 16000 ha including the monitoring VA sub-site (Fig. 1). All ploughed fields (an area of c. 3000 ha), i.e. those sown with sunflower or maize (vegetation height under $15 \mathrm{~cm}$ ), were systematically inspected for 1-5 minutes according to field size and topography. Observations were carried out at the beginning of May over 8-15 days (the precise dates varied from year-to-year according to spring crop growth). Since the LTSER is very varied in topography and cropping systems, there were substantial differences between the four sub-sites. Observations were always performed in good sighting conditions (no heavy rainfall or heat haze), usually 7-11 a.m. and 4-8 p.m. Since detection probability was not accounted for, we measured apparent population size rather than true population size. We used a GLM with a Poisson errordistribution (and log link) with a hypothesis testing approach (i.e. based on p-value with $\alpha=$ 0.05), to test for the temporal trend in abundance, number of pairs detected (simply defined as two birds seen together in the same field) and number of fields occupied by one or more

birds. Explanatory variables included: sub-site identity (a factor with four levels), year (as a 
continuous variable) as well as their interaction. In addition, the surface of the surveyed area and the number of fields surveyed, which varied between years and sub-sites, were entered as offsets after log-transformation. Because $75 \%$ of the observers were involved in just one year, and only $5 \%$ more than three years, we did not include observer identity in a mixed effect modelling framework. We investigated whether residuals displayed spatial autocorrelation thanks to a spatial variogram (R package 'spatial', Venables \& Ripley 2002). The exponential growth rate of the abundance was extracted from the year term.

The second monitoring survey relied on the breeding biology monitoring scheme (see above) and concerned only the VA sub-site, where a thorough nest search was carried out every year from March to June. The long-term trend in number of nests was tested using a generalized additive model with a smoothed term on the year (GAM, Gaussian error distribution) and a hypothesis testing approach (based on $P$-value with $\alpha=0.05$ ). However, since the monitored period differed slightly between years, we tabulated the number of pairs

for the extended period $\left(15^{\text {th }}\right.$ Marsh $-30^{\text {th }}$ June) and for reduced, better standardised periods: $15^{\text {th }}$ Marsh $-30^{\text {th }}$ May, and $1^{\text {st }}$ April $-10^{\text {th }}$ May.

\section{Survival rates}

Stone-curlews were captured in the monitored breeding sub-site VA from 2005 between March and September. Birds were ringed with a metal ring (National Museum of Natural History, MNHN, Paris, France) and a combination of 2 or 4 colour rings (http://crbirding.org/node/89). Chicks were ringed only if older than 10 days. Between 2005 and 2015, 93 adults and 68 chicks/fledglings were ringed, yielding to a total of 254 re-sightings. Adult body weight $(\mathrm{g})$ and wing length $(\mathrm{mm})$ were measured for captures $(n=57)$ and recaptures $(n=6)$. Body condition was estimated using the scale mass index (SMI) that explicitly accounts for the allometric relationships (Peig \& Green 2009). Body mass was standardized for a given size using the following equation:

$$
\widehat{\mathrm{M}}_{\mathrm{i}}=\mathrm{M}_{\mathrm{i}} *\left[\frac{\mathrm{L}_{0}}{\mathrm{~L}_{\mathrm{i}}}\right]^{\mathrm{b}_{\text {sma }}}
$$


where $\widehat{\mathrm{M}}_{\mathrm{i}}$ is the predicted body mass for individual $\mathrm{i}$ when the body measure is standardized to $\mathrm{L}_{0}$, an arbitrary value of $\mathrm{L} . \mathrm{M}_{\mathrm{i}}$ and $\mathrm{L}_{\mathrm{i}}$ are the body mass and the body measurement of individual i respectively; $b_{\text {sma }}$ is the scaling exponent estimated.

Survival estimates were obtained by capture-recapture analysis using a CormackJolly-Seber model. Parameters directly estimated by the model were $\phi$, the apparent survival probability, and $p$, the re-sighting probability. To avoid over-parameterization, we used a twostep model selection procedure. First, we selected the best model structure based on a full general model with an AICc-based model selection. Second, we assessed the presence of a trend over the study period on juvenile and adult survival, and tested the possible effect of body condition at capture year $t$ on adult survival in year $t+1$. In our general model, survival probability was age- and sex-dependent. For the effect of age, we distinguished 2 classes, juvenile (first year), and adult (> 1 year; Green et al. 1997). Re-sighting probability was time and sex-specific, because brooding is mainly performed during the day by the female (preventing rings to be read), and the male is predominantly in the 'spotter' position (pers. obs.). We considered only an additive effect of time for re-sighting probability because an interactive effect with sex leads to an over parameterized model. Thus our general model was $\phi_{\text {juv.sex ad.sex }} \mathrm{p}_{t+\text { sex }}$ where juvenile is denoted by 'juv', adult by 'ad', additive effect by '+' and interactive effect by ' '.To assess the effect of body condition on survival, we included in the best model the logistic regression: $\operatorname{logit}(\Phi)=\beta 0+\beta 1^{*} x_{i}$, where $\Phi$ is the survival probability the year following the first capture, $\beta 0$ is an intercept parameter, $\beta 1$ is a slope parameter, and $x_{i}$ is the body condition of individual $i$ at first capture time. Model building, model selection (AICc, Burnham \& Anderson 2002) and parameter estimates were obtained using E-SURGE (v.1.8.5, Choquet et al. 2009a). The model selection method was identical to that presented above (see section on breeding biology). Following Grosbois et al. (2008), we used a likelihood ratio test (LRT, hypothesis testing approach, $\alpha=0.05$ ) to estimate the significance of a trend in survival since residual survival variation is null after integrating. We performed goodness-of-fit (GOF) tests using program U-CARE (v.2.3.2, Choquet et al. 2009b). Finally, the temporal trend in body condition index was tested under a hypothesis 
testing approach $(\alpha=0.05)$ with a linear mixed effect model $(L M M)$, with year and date of capture as fixed effects and individual as a random effect.

All statistical analyses were run on R 3.2.0 (R Development Core Team 2015). For LM, GLM and LMM, residuals of the models were checked using graphical methods in order to verify the assumptions of normality, non-overdispersion and homoscedasticity. Means are presented \pm sd unless stated.

\section{RESULTS}

\section{Breeding biology}

Over the 19 survey years, 566 nests were found, of which 513 provided an estimated laying date. Nests with at least one ringed bird $(n=130)$ allowed us to confirm the existence of true second clutches after a successful attempt (i.e. double brooding, $n=5$ ) and even that of pairs having three successive breeding attempts $(n=2)$. After successful fledging (at the age of 50 days, Green et al. 1997) or a breeding failure, a new reproductive attempt was started on average $13.5 \pm 4.2$ days later (range $10-20$ days, $n=5$ ). The first peak of laying dates was around the $18^{\text {th }}$ of April (Fig. 2, median of the log-normal distribution around the $27^{\text {th }}$ of April \pm 17 days), with the earliest clutch being laid on the $15^{\text {th }}$ of March. The second peak of laying dates was around the $22^{\text {th }}$ of May (Fig. 2, median of the log-normal distribution around the $25^{\text {th }}$ of May \pm 11 days). A few late clutches were laid by the end of June (Fig. 2). Some laying occurred up to mid-September, although these were not included in the analysis for protocol consistency ( $<3 \%$ of nests). The mixture distribution model provided an estimate of $1.17 \pm 0.11$ breeding attempts per pair $\left(X^{2}{ }_{5}=5.66, P=0.34\right)$. Most clutches $(85.0 \%, n=533)$ were 2-egg clutches (mean $1.85 \pm 0.36$ eggs), although some 1-egg clutches may have been 2-egg clutches subject to accidental loss or partial predation. On average, 2-egg and 1-egg clutches were visited respectively $9.9 \pm 6.9$ days and $13.0 \pm 7.7$ days after the laying date. In addition, the first visit occurred in the first three days after laying for $24 \%$ and $14 \%$ of the 2 egg and 1-egg clutches, respectively. 
On average, raw hatching success was $53 \pm 15 \%$, reduced to $32 \pm 3 \%$ after correction using the Mayfield method $(n=441)$. Desertion/predation accounted for $85 \pm 3 \%$ of clutch failures, while direct destruction caused by mechanical agricultural work caused 15 $\pm 3 \%$ of failures. Once nests were discovered, however, they were marked and farmers were immediately informed and asked to avoid them during farm work. The proportion of nests lost due to agricultural activity is expected to be higher during the period between egg laying and nest detection, and therefore, nest destruction from sowing or hoeing was probably underestimated. There was no strong evidence that clutch size had an effect on nest survival, nor on the cause of failure (i.e. each model including clutch size had $\triangle \mathrm{AICc}>2$, Table 1, SOM4).

\section{Long-term and seasonal trends in breeding parameters}

Model selections provided support for a temporal trend for all breeding parameters, except laying date (Table 1). We found that nest survival and egg volume had declined over the study duration by $80 \%$ and $2 \%$ respectively (Fig. 3). Decrease in nest survival over the years was the consequence of increasing desertion/predation rate that varied from $30 \pm 9 \%$ at the beginning of the study period to $80 \pm 4 \%$ during the last years. Over the same period, destruction rate was relatively stable at around $11 \pm 4 \%$ (SOM5). Results suggested an increase in clutch size through time, but evidence for this trend was weak since the constant model was also in the best model set $(\triangle \mathrm{AICc}=0.8)$. Within years, we found a clear support for a seasonal trend in all breeding parameters, except clutch size (Table 1, SOM4). Nest survival and egg volume decreased over the breeding season (Table 1). The cause of failure also changed, with the highest proportion of nests lost due to desertion/predation for late

clutches (Table 1, SOM6). Finally, the results provided moderate support for a positive interaction between laying date and year on nest survival and egg volume $(\triangle \mathrm{AICc}=2$ and 1 , respectively) suggesting that the negative seasonal trend previously described has been 
attenuated over the study duration (Table 1). An interaction between laying date and year was not supported as the cause of failure and clutch size (Table 1, SOM4).

\section{Trends in apparent population size}

Using data from the four sub-sites, we found that abundance decreased significantly over the 14 years (Fig. 3, GLM, $\beta=-0.03, z=-3.1, P=0.002$ ) with an exponential growth rate of $r=$ $0.979,95 \% \mathrm{Cl} 0.958-0.989$. The same results were verified for the number of pairs detected (GLM, $\beta=-0.03, z=-2.0, P=0.05$ ) and for the number of occupied fields (GLM, $\beta=-0.03, z$ $=-2.9, P=0.004)$. The sub-site effect was significant as well as its interaction with year for the three investigated variables (total abundance, number of pairs and number of occupied fields, $P<0.0001)$. In the VA sub-site, the values were significantly higher and trends were more negative $(P<0.0001)$. The PR sub-site, outside of the SPA, was not significantly different to the FO and SB sub-sites in mean or interaction effects $(P>0.4)$. No significant linear or polynomial trends were detected for the number of nests found at the VA sub-site, irrespective of the survey period retained (GAM, $P>0.05$; SOM7).

\section{Survival rates}

Goodness of fit tests $\left(X^{2}=52.7, P=0.60\right)$ provided no indication of lack of fit. The first step of model selection suggested that resighting probability was time- and sex-specific (Table 2). As expected, males had an average resighting probability higher than females' (males 0.76 , $95 \% \mathrm{Cl}$ 0.62-0.86; females $0.53,95 \% \mathrm{Cl} 0.38-0.67)$. We did not find any evidence for sexspecific survival rates, but there was strong support for different apparent survival rates between juveniles and adults (Table 2, M5 vs. M8 $\triangle \mathrm{AICc}=14.92$ ). Juvenile survival was 0.55 (95\% Cl 0.41-0.69) and adult survival was $0.88(95 \% \mathrm{Cl} 0.83-0.91)$. For the second step of the model selection, LRT supported a linear trend in adult survival over the study period $\left(F_{\text {cst/trend/t }}=8.11, P=0.004 ;\right.$ SOM8 $)$, with an average decrease in apparent survival of $2.3 \%$

per year (Fig. 3). Finally, adult body condition index (average mass $=490.0 \pm 38.6 \mathrm{~g}$ ) 
decreased, but not significantly, over the study period (LMM, $\beta=-2.00, t_{1,89}=-1.67, P=$ 0.23). We found a positive relationship between body condition and female adult survival (SOM8).

\section{DISCUSSION}

Our study provides detailed information on the breeding biology and population trends of the Stone-curlew using one of the longest time-series available, and the only available one for France. In addition, the study was located in one of the strongholds of the species, the Poitou-Charentes region that harbours c.13-21\% of the French population (Issa \& Muller 2015). Our results indicate a long-term decline in this population. Such a decline, despite ongoing conservation efforts, questions the overall sustainability of arable Stone-curlew populations.

\section{Breeding success and survival rate in an intensive farmland landscape}

Within a European context, the observed nest survival rate and survival of individuals in this study are comparable to those obtained for the UK, Spain and Italy (SOM9). Nest destruction through agricultural work was responsible for $11 \%$ of nest failures in our study, which mainly occurred at a very early stage of incubation, i.e. before signalling the nest's presence to the farmers, and which is underestimated. The rate of nest destruction without protection was estimated at 33\% in 2001 and nearly 50\% in 2012 (unpubl. data), thus constituting the major threat encountered by the species in such farmland habitat. Additionally, predation has been reported as the main cause of nest failure (Solis \& Lope 1995, Bealey et al. 1999), and probably accounts for most of the desertion/predation events reported in this study, even if the effect of crop growth was not estimated. Some 1-egg clutches could also have resulted from partial egg predation before the first nest visit. The increase in desertion/predation over time could result either from a reduction in nest protection, given that parents in weak body 
condition cannot ensure proper parental care such as nest defence or nest attendance after predator encounters (Winkler 1992), or by an increase in the populations of predators.

\section{The long term decline of the Stone-curlew in intensive farmlands}

All investigated demographic parameters displayed negative trends over time. Although apparent rather than true survival rate was estimated, which may not exclude permanent emigration from the study area (an unlikely scenario given the species is known to be highly philopatric; Green 1990), a decrease in adult survival is of concern for population stability since population growth rate is highly sensitive to adult mortality in long-lived species (Sæther \& Bakke 2000). While this study took place at a relatively small spatial scale (c. 4 300 ha), which may limit the generality of the conclusions, this population benefited from AES dedicated to the preservation of trophic resources for farmland birds (Bretagnolle et al. 2011) and from active nest protection from agricultural work. Consequently, the decrease in breeding success and survival which resulted in a rapid population decline (26\% in 14 years) that occurred in what could be described as the best current possible conditions for the species in intensive French agricultural landscapes.

Which factors, affecting both survival and breeding process, may have caused the population decline? As suggested, nest destruction during sowing or mechanical weeding is a well known major factor, but with limited impact in our case thanks to the nest awareness program. In addition, we suggest that food limitation may play an important, often overlooked, role. Of particular interest in this respect is the decrease in egg volume ( $2 \%$ in 19 years), despite AES implementation since the first years of monitoring, enhancing overall habitat quality (Bretagnolle et al. 2011). Within a given season, a decrease in egg volume is found in many bird species, as in our population, due to early breeders being of higher quality than late ones (Christians 2002, Verhulst \& Nilsson 2008). However, food availability can also affect egg volume (Robb et al. 2008). Agricultural intensification is considered a key factor which negatively impacts the diversity and abundance of insects (Donald et al. 2001, Johnson 2007, Geiger et al. 2010). Recent studies have demonstrated relationships between 
widespread application of pesticides, neonicotinoids in particular, with concomitant declines in insect and plant communities, and decreases in insectivorous or granivorous birds (Mineau \& Whiteside 2013 , Hallmann et al. 2014, Gilburn et al. 2015). The diet of the Stonecurlew is based on earthworms and beetles (Amat 1986, Green et al. 2000). Even though a detailed analysis of food availability and diet may be lacking in our study, it is perhaps relevant to note that Poecilus cupreus, the most abundant carabid species in our study site (Marrec et al. 2016) has shown an average 80\% decline in 20 years (unpubl. data). A further mechanism which may be involved in the decrease in adult survival is that of carry-over effects in wintering areas (Harrison et al. 2011). Preliminary data from GPS tracking of our breeding population has indicated a fairly high diversity of wintering sites (France, Portugal and Morocco, unpubl. data).

\section{Implications for conservation}

The French Stone-curlew population has been claimed to have increased in the period 20012011 (BirdLife 2017). We question this conclusion, especially given the absence of standardised and dedicated protocols to monitor Stone-curlew in France, and the cryptic nature of the species. We suggest these positive trends actually result from an increase in survey quality, i.e. a better knowledge of the species' habitat, and better data transfer from observers (Issa \& Muller 2015). Based on our results, we suggest that Stone-curlews breeding in farmland habitats may be currently declining. Indeed, many farmland birds, especially the largest species, are currently highly threatened. For some, a dedicated AES framework has proved useful (e.g. Verhulst et al. 2007, Bretagnolle et al. 2011), despite AES having been much criticised in the early years of implementation (Kleijn \& Sutherland 2003). AES dedicated to Stone-curlews are non-existent in France, while in the UK, such AES consist of fallow plots providing suitable breeding and foraging areas (Natural England 2010). In our study area, however, we expected the species to have potentially benefited from AES dedicated to the Little Bustard. Such practices may provide suitable habitat for the Stonecurlew, and improve food availability (Bretagnolle et al. 2011, Caro et al. 2016). However, 
despite the fact that up to 10000 ha of AES were established within the LTSER (43 $000 \mathrm{ha}$ ), Stone-curlew demographic parameters have been declining. AES at a field scale may not be appropriate because this species forages over large areas (Green et al. 2000). Nevertheless, AES for Stone-curlews can work, as the RSPB Stone-curlew program has successfully demonstrated (Evans \& Green 2007). However, the success of this latter program required a strong investment in fieldworkers, applied research, networking and funds for some hundreds of breeding pairs.

In our case, there are possible efficient conservation measures that could be implemented at a far larger spatial scale. Given the current restricted knowledge of this species, there is a clear and urgent need to accurately evaluate whether this decline is general (at the nation-wide scale), or restricted to some specific agricultural areas. Implementing long-term monitoring of demography and breeding parameters in this and other French populations is therefore needed to assess the potentially widespread and generic decline of the species, not only in arable farmland landscapes, but also in all seminatural or artificial habitats. This would require an assessment of: 1) the spatial distribution and population size at the country scale; 2) local/regional population trends in several habitats; 3) diet in and outside the breeding season; 4) the effects of predation and human disturbance; 5) exposure to pesticides; and, 6) migratory strategies.

The creation of safe habitats to reduce brood destruction and promote food availability, based on the UK experience (Thompson et al. 2004), should be explored. If similar patterns of population decline were to be confirmed in other parts of France, such conservation plots should be established over hundreds of thousands of hectares to be efficient, given the very large breeding distribution of Stone-curlew. It should be also adapted to a range crops (e.g. maize, sunflower, grasslands, vineyard). This would be challenging, since it would require either pro-active campaigns targeting farmers to adopt voluntary practices, or a consistent funding scheme to compensate for the potential yield loss of farmers at very large scale (Evan \& Green 2007), in a context of budgetary restriction in agricultural subsidies. Alternatively, we may target the species' environment and habitat 
rather than the species itself. For instance, in order to improve food availability, a reduction or ban of inputs may be targeted. Some AES, organic farming, or the recent complete ban of neonicotinoids in France, may help. An increase of perennial crops, such as grasslands, and the enhancement of more extensive practices, should be strongly promoted as they support higher prey resources (Bretagnolle et al. 2011, Badenhausser et al. 2012, Caro et al. 2016).

We would like to thank C. Attié, V. Rocheteau, M. Liaigre, R. Bonnet, A. Millon, A. Desternes, as well as all fieldworkers who have helped to collect this data over the years and spent much time on field, and L. Inchboard for improving English. Partial funding was allocated by DREAL Poitou-Charentes and Fondation LISEA to VB. We also thank reviewers for their very helpful comments and suggestions.

\section{REFERENCES}

Aebischer, N. J., \& Ewald, J. A. 2012. The grey partridge in the UK: population status, research, policy and prospects. Anim. Biodivers. Conserv., 35(2), 353-362.

Amat, J.A. 1986. Information on the diet of the Stone Curlew Burhinus oedicnemus in Doñana, southern Spain. Bird Study, 33, 71-73.

Badenhausser, I., and Cordeau, S. 2012. Sown grass strip—A stable habitat for grasshoppers (Orthoptera: Acrididae) in dynamic agricultural landscapes. Agric., Ecosyst. \& Environ., 159, 105-111.

Barré, K., Le Viol, I., Julliard, R. \& Kerbiriou, C. 2018. Weed control method drives conservation tillage efficiency on farmland breeding birds. Agric., Ecosyst. \& Environ., 256, 74-81

Bealey, C.E., Green, R.E., Robson, R, Taylor, C.R. and Winspear, R. 1999. Factors affecting the numbers and breeding success of Stone Curlews Burhinus oedicnemus at Porton Down, Wiltshire. Bird Study, 46, 145-156. 
Berg, Å., Jonsson, M., Lindberg, T., and Källebrink, K. G. 2002. Population dynamics and reproduction of Northern Lapwings Vanellus vanellus in a meadow restoration area in central Sweden. Ibis, 144, 131-140.

Berthet, E. T., Bretagnolle, V, and Segrestin, B. 2012. Analyzing the design process of farming practices ensuringlittle bustard conservation: lessons for collective landscape management. J. Sustain. Agri., 36: 319-336.

BirdLife International. 2017. European birds of conservation concern: populations, trends and national responsibilities. Cambridge, UK: BirdLife International.

Bretagnolle, V., Villers, A., Denonfoux, L., Cornulier, T., Inchausti, P. and Badenhausser, I. 2011. Rapid recovery of a depleted population of Little Bustards Tetrax tetrax following provision of alfalfa through an agri-environment scheme. Ibis, 153, 4-1.

Bretagnolle, V., Berthet, E., Gross, N., Gauffre, B., Plumejeaud, C., Houte, S., Badenhausser, I., Monceau, K., Allier, F., Monestiez, P. and Gaba, S. 2018. Towards sustainable and multifunctional agriculture in farmland landscapes: Lessons from the integrative approach of a French LTSER platform. Sci. Total Environ.. 627, 822 - 834

Brodier, S., Augiron, S., Cornulier, T., and Bretagnolle, V. 2014. Local improvement of skylark and corn bunting population trends on intensive arable landscape: a case study of the conservation tool Natura 2000. Anim. Conserv., 17(3), 204-216.

Burnham, K.P. and Anderson, D.R.. 2002. Model selection and multimodel inference: a practical information-theoretic approach, 2nd edn. Springer, New York.

Caro, G., Marrec, R., Gauffre, B., Roncoroni, M., Augiron, S. and Bretagnolle, V. 2016. Multiscale effects of agri-environment schemes on carabid beetles in intensive farmland. Agric., Ecosyst. \& Environ., 229, 48-56.

Chamberlain, D.E., Fuller, R.J., Bunce, R.G.H., Duckworth, J.C. and Shrubb, M. 2000. Changes in the abundance of farmland birds in relation to the timing of agricultural intensification in England and Wales. J. Appl. Ecol., 37, 771-788. 
Chiron, F., Chargé, R., Julliard, R., Jiguet, F. and Muratet, A. 2014. Pesticide doses, landscape structure and their relative effects on farmland birds. Agric., Ecosyst. \& Environ., 185, 153-160

Choquet, R., Rouan, L. and Pradel, R. 2009a. Program E-SURGE: a software application for fitting Multievent models Series. Environ. and Ecol. Stat., 3, 845-865.

Choquet, R., Lebreton, JD., Gimenez, O., Reboulet, A-M. and Pradel, R. 2009b. U-CARE: utilities for performing goodness of fit tests and manipulating CApture-REcapture data. Ecography, 32, 1071-1074.

Christians, J.K. 2002. Avian egg size: variation within species and inflexibility within individuals. Biol. Rev., 77, 1-26.

Cramp, S. and Simmons, K.E.L. 1983. The Birds of the Western Palearctic Volume III. Oxford University Press, New York.

Darrah, A.J., Cohen, J.B. and Castelli, P. M. 2018. A Bayesian multinomial logistic exposure model for estimating probabilities of competing sources of nest failure. Ibis, 160, 23-35.

Donald, P.F., Green, R.E. and Heath, M.F. 2001. Agricultural intensification and the collapse of Europe's farmland bird populations. Proc. R. Soc. Lond. B, 268, 25-29.

Eaton, M.A., Balmer, D.E., Cuthbert, R., Grice, P.V., Hall, J., Hearn, R.D., Holt, C.A., Musgrove, A.J., Noble, D.G., Parsons, M., Risely, K., Stroud, D.A. and Wotton, S. 2011. The state of the UK's birds 2011. RSPB, BTO, WWT, CCW, JNCC, NE, NIEA \& SNH, Bedfordshire.

Evans, A.D. and Green, R.E. 2007. An example of a two-tiered agri-environment scheme designed to deliver effectively the ecological requirements of both localized and widespread bird species in England. J. Ornithol., 148, 279-286.

Fuller, J., Gregory, R.D., Gibbons, D.W., Marchant, J.H., Wilson, I.D., Baillie, S.R. and Carter, N. 1995. Population declines and range contractions among lowland farmland birds in Britain. Cons. Biol., 9, 1425-1441.

Geiger, F., Bengtsson, J., Berendse, F., Weisser, W.W., Emmerson, M., Morales, M.B., Ceryngier, P., Liira, J., Tscharntke, Teja., Winqvist, C., Eggers, S., Bommarco, R., Pärt, 
T. Bretagnolle, V., Plantagenest, M., Clement, L.W., Dennis, C., Palmer, C., Oñate, J.J., Guerrero, I., Hawro, V., Aavik, T., Thies, C., Flohre, A., Hänke, S., Fischer, C., Goedhart, P.W and Inchausti, P. 2010. Persistent negative effects of pesticides on biodiversity and biological control potential on European farmland. Basic App. Ecol., 11, 97-105.

Gilburn, A.S., Bunnefeld, N., Wilson, J.M., Botham, M.S., Brereton, T.M., Fox, R. and Goulson, D. 2015. Are neocotinoid insecticides driving declines of widespread butterflies? PeerJ 3:e1402

Gibbons, D.W., Avery, M., Baillie, S., Gregory, R., Kirby, J., Porter, R., Tucker, G. and Williams,G. 1996. Bird Species of Conservation Concern in the United Kingdom, Channel Isles and Isle of Man: revising the Red Data List. RSPB Conservation Review No 10, Bedfordshire.

Green, R.E. 1990. Saving the stone curlew. Sanctuary bulletin, 19, 37-39.

Green, R.E. and Griffiths, G.H. 1994. Use of preferred nesting habitat by stone curlews Burhinus oedicnemus in relation to vegetation structure. J. Zool., 233, 457-471.

Green, R.E., Hodson, D.P. and Holness, P.R. 1997. Survival and movements of Stone Curlews Burhinus oedicnemus ringed in England. Ring. Migr., 18, 24-34.

Green, R.E., Tyler, G.A. and Bowden, C.G.R. 2000. Habitat selection, ranging behavior and diet of the stone curlew (Burhinus oedicnemus) in southern England. J. Zool., 250, 161183.

Grice, P., Radley, G., Smallshire, D., Green, M. 2007. Conserving England's arable biodiversity through agri-environment schemes and other environmental policies: a brief history. Asp. Appl. Biol., 81, 7-22.

Grosbois, V., Gimenez, O., Gaillard, J.-M., Pradel, R., Barbraud, C., Clobert, J., Møller, A. P. and Weimerskirch, H. 2008. Assessing the impact of climate variation on survival in vertebrate populations. Biol. Rev., 83, 357-399.

Hallmann, C.A., Foppen, R.P.B, van Turnhout, C.A.M, de Kroon, H. and Jongejans, E. 2014. Declines in insectivorous birds are associated with high neonicotinoid concentrations. Nature 511, 341-343. 
Harrison, X.A, Blount, J.D., Inger, R., Norris, D.R. \& Bearhop, S. 2011. Carry-over effects as drivers of fitness differences in animals. J. Anim. Ecol. 80, 4-18.

Heldbjerg, H., Sunde, P., and Fox, A. D. 2017. Continuous population declines for specialist farmland birds 1987-2014 in Denmark indicates no halt in biodiversity loss in agricultural habitats. Bird Conserv. Int., 1-15.

Hoyt, D. F. 1979. Practical methods of estimating volume and fresh weight of bird eggs. The Auk, 73-77.

INRA. 1998. La base de données géographique des sols de France au 1/1 000000 . Inra, Service d'étude des sols et de la carte pédologique de France.

Issa, N. and Muller, Y. 2015. Atlas des oiseaux de France métropolitaine; nidification et présence hivernale. Delachaux \& Niestlé, Paris.

Johnson, M.D. 2007. Measuring habitat quality: a review. Condor, 109, 489-504.

Kaplan, O.J., Krumhardt, K.M. and Zimmermann, N. 2009. The prehistoric and preindustrial deforestation of Europe. Quat. Sci. Rev., 28, 3016-3034.

Kentie, R., Hooijmeijer, J. C., Trimbos, K. B., Groen, N. M. and Piersma, T. 2013. Intensified agricultural use of grasslands reduces growth and survival of precocial shorebird chicks. J. Appl. Ecol., 50, 243-251.

Kleijn, D. and Sutherland, W. 2003. How effective are European agri-environmental schemes in conserving and promoting biodiversity? J. Appl. Ecol., 40, 947-963.

Krebs, J.R., Wilson, J.D, Bradbury, R.B. and Siriwardena, G.M. 1999. The second silent spring? Nature, 400, 611-612.

Macdonald, P., \& Du, J. 2012. mixdist: finite mixture distribution models. R package version 0.5-4. 2011- 05- 16)[2013- 02- 08]. http://cran. r- project. org/web/packages/mixdist/index. html.Malvaud, F. 1996. L'Oedicnème criard en France, (Burhinus oedicnemus). Groupe Ornithologique Normand, Caen.

Marrec, R. Badenhausser, I., Bretagnolle, V., Börger, L., Roncoroni, M., Guillon, N. and Gauffre, B. 2015. Crop succession and habitat preferences drive the distribution and 
abundance of carabid beetles in an agricultural landscape. Agric., Ecosyst. \& Environ., 199, 282-289.

Mayfield, J. 1975. Suggestions for calculating nest success. Wilson Bulletin, 87, 456-466.

Mineau, P. and Whiteside, M. 2013. Pesticide acute toxicity is a better correlate of U.S. grassland bird declines than agricultural intensification. PLoS ONE 8(2): e57457.

O'Connor, R.J. and Shrubb, M. 1986. Farming and Birds. Cambridge University Press, Cambridge.

Natural England, 2010a. Entry Level Stewardship: Environmental Stewardship

Handbook, third ed. - February 2010.

Peig, J., and Green, A. J. 2009. New perspectives for estimating body condition from mass/length data: the scaled mass index as an alternative method. Oikos, 118, 18831891.

Powell, L. A. 2007. Approximating variance of demographic parameters using the delta method: a reference for avian biologists. The Condor, 109(4), 949-954.

R Development Core Team 2015. R: A Language and Environment for Statistical Computing. R Foundation for Statistical Computing, Vienna.

Rands, M.R.W. 1985. Pesticide use on cereals and the survival of grey partridge chicks: a field experiment. J. Appl. Ecol. 22, 49-54.

Robb, G.N., McDonald, R.A., Chamberlain, and D.E., Bearhop, S. 2008. Food for thought: supplementary feeding as a driver of ecological change in avian populations. Front. Ecol. \& Environ., 6, 476-484.

Rotella, J.J. 2014. Nest survival models. In Cooch, E. \& White, G., eds. Program MARK: a gentle introduction. Chapter 17.20 p. Available at: http://www.phidot.org/software/mark/docs/book/.

Sæther, B. E., and Bakke, Ø. 2000. Avian life history variation and contribution of demographic traits to the population growth rate. Ecology, 81, 642-653. 
Stanton, R.L., Morrissey, C.A. and Clark, R.G. 2018. Analysis of trends and agricultural drivers of farmland bird declines in North America: A review. Agric., Ecosyst. \& Environ., $254,244-254$.

Thompson, S., Hazel, A., Bailey, N., Bayliss, J., and Lee, J. T. 2004. Identifying potential breeding sites for the stone curlew (Burhinus oedicnemus) in the UK. Agric., Ecosyst. \& Environ., 12, 229-235.

Verhulst, J., Kleijn, D. and Berendse, F. 2007. Direct and indirect effects of the most widely implemented Dutch agri-environment schemes on breeding waders. J. Appl. Ecol., 44, 70-80.

Verhulst, S. and Nilsson, J-Å. 2008. The timing of birds' breeding seasons: a review of experiments that manipulated timing of breeding. Philosoph. Transact. R. Soc. Lond., 363, 399-410.

Vaughan, R. and Vaughan-Jennings, N. 2005. The Stone Curlew Burhinus oedicnemus. Isabelline Books, Falmouth.

Venables, W. N. \& Ripley, B. D. 2002. Modern Applied Statistics with S. Fourth Edition. Springer, New York. ISBN 0-387-95457-0

Whittingham, M.J., and Evans, K.L. 2004. The effects of habitat structure on predation risk of birds in agricultural landscapes. Ibis, 146, 210-220.

Winkler, D.W. 1992. Causes and consequences of variation in parental defence behaviour by tree swallows. Condor, 94, 502-520.

Yeatman-Berthelot, D. and Jarry, G. 1994. Nouvel Atlas des Oiseaux nicheurs de France. 1985-1989. Société Ornithologique de France, Paris.

Yu, Y. L., Wu, X. M., Li, S. N., Fang, H., Zhan, H. Y. and Yu, J. Q. 2006. An exploration of the relationship between adsorption and bioavailability of pesticides in soil to earthworm. Environmental pollution, 141, 428-433 
Table 1. Results from model selection testing for a linear effect of time (period 19982016) on laying date (LD), nest survival, nest desertion/predation probability given failure, clutch size and egg volume. Tested variables include the laying date ('LD') for all breeding parameters, excluding the laying date, and clutch size ('CS') for nest survival and nest desertion/predation probability given failure. For each model results include the number of parameters (k), deviance (DEV), AIC value corrected for small-sample-size (AICc), difference between current model and the best model within each sub-set of model $(\triangle \mathrm{AICc})$ and the estimated slope and intercept \pm se of the highest ranked model. '+' indicates additive effect and ':' an interaction. All covariates were standardized. Only the highest ranked models $(\triangle \mathrm{AICc} \leq 2)$ are shown. Details of other models are given in SOM4.

\begin{tabular}{|c|c|c|c|c|c|c|c|}
\hline Model & $\mathrm{k}$ & DEV & $\mathrm{AICc}$ & $\triangle \mathrm{AICc}$ & Slope 1 & Slope 2 & Interaction \\
\hline \multicolumn{8}{|c|}{ Laying date (March-June) } \\
\hline constant model & 1 & 4492.6 & 4496.7 & 0.0 & & & \\
\hline year & 2 & 4491.8 & 4497.8 & 1.1 & $-0.21 \pm 0.14$ & & \\
\hline \multicolumn{8}{|c|}{ Laying date (March-27 ${ }^{\text {th }}$ April) } \\
\hline constant model & 1 & 1702.2 & 1706.2 & 0.0 & & & \\
\hline year & 2 & 1701.2 & 1707.2 & 1.0 & $0.10 \pm 0.10$ & & \\
\hline \multicolumn{8}{|l|}{ Nest survival } \\
\hline year + LD + year:LD & 10 & 1245.0 & 1265.0 & 0.0 & $-0.95 \pm 0.27$ & $-0.42 \pm 0.16$ & $0.53 \pm 0.27$ \\
\hline year + LD & 9 & 1249.0 & 1267.0 & 2.0 & $-0.44 \pm 0.08$ & $-0.15 \pm 0.08$ & \\
\hline \multicolumn{8}{|c|}{ Nest desertion/predation probability given failure } \\
\hline year + LD & 10 & 1245.0 & 1265.0 & 0.0 & $0.79 \pm 0.25$ & $0.85 \pm 0.25$ & \\
\hline year + LD + year:LD & 11 & 1244.7 & 1266.8 & 1.8 & $0.39 \pm 0.79$ & $0.63 \pm 0.47$ & $0.49 \pm 0.92$ \\
\hline \multicolumn{8}{|l|}{ Clutch size } \\
\hline year & 2 & 399.3 & 403.4 & 0.0 & $0.22 \pm 0.13$ & & \\
\hline constant model & 1 & 402.2 & 404.2 & 0.8 & & & \\
\hline year + LD & 3 & 398.9 & 404.9 & 1.5 & $0.22 \pm 0.13$ & $-0.09 \pm 0.13$ & \\
\hline \multicolumn{8}{|l|}{ Egg volume } \\
\hline year + LD + year:LD & 4 & 4052.2 & 4062.3 & 0.0 & $-0.23 \pm 0.10$ & $-0.57 \pm 0.10$ & $0.19 \pm 0.09$ \\
\hline year + LD & 3 & 4055.2 & 4063.2 & 1.0 & $-0.22 \pm 0.10$ & $-0.57 \pm 0.10$ & \\
\hline
\end{tabular}


Table 2. Survival $(\phi)$ and resighting (p) modelling as a function of age and sex between 2005 and 2015. Results of model selection include: number of mathematical parameters $(\mathrm{k})$, the deviance (Dev), AIC value corrected for small-sample-size (AICc) and difference between current model and the best model within each sub-set of model $(\triangle \mathrm{AICc})$. The final selected model is in bold characters. For model notation, 'juv' indicates juvenile, 'ad' indicates adult, 'cst' indicates a constant parameter, '+' indicates an additive effect and '?' indicates interactive effect.

\begin{tabular}{|c|c|c|c|c|c|}
\hline No. & Model & $\mathrm{k}$ & DEV & AICc & $\triangle \mathrm{AICc}$ \\
\hline & Resighting & & & & \\
\hline 1 & $\mathrm{p}_{\text {sex }+t}$ & 22 & 797.43 & 844.02 & 0 \\
\hline 2 & $\mathrm{p}_{\text {sex }}$ & 10 & 826.31 & 846.85 & 2.84 \\
\hline 3 & $\mathrm{p}_{t}$ & 21 & 802.57 & 846.93 & 2.91 \\
\hline 4 & $\mathrm{p}_{c s t}$ & 9 & 831.31 & 849.76 & 5.74 \\
\hline & Survival: sex ef & & & & \\
\hline 5 & $\phi_{j u v_{-} a d}$ & 20 & 798.07 & 840.21 & 0 \\
\hline 6 & $\phi_{j u v . s e x_{-} a d}$ & 21 & 797.76 & 842.11 & 1.90 \\
\hline 7 & $\phi_{j u v \_a d . s e x}$ & 21 & 797.80 & 842.16 & 1.95 \\
\hline 1 & $\phi_{\text {juv.sex_ad.sex }}$ & 22 & 797.43 & 844.02 & 4.78 \\
\hline & Survival: age ef & & & & \\
\hline 5 & $\phi_{j u v_{-} a d}$ & 20 & 798.07 & 840.21 & 0 \\
\hline 8 & $\phi_{c s t}$ & 19 & 815.20 & 855.13 & 14.92 \\
\hline
\end{tabular}




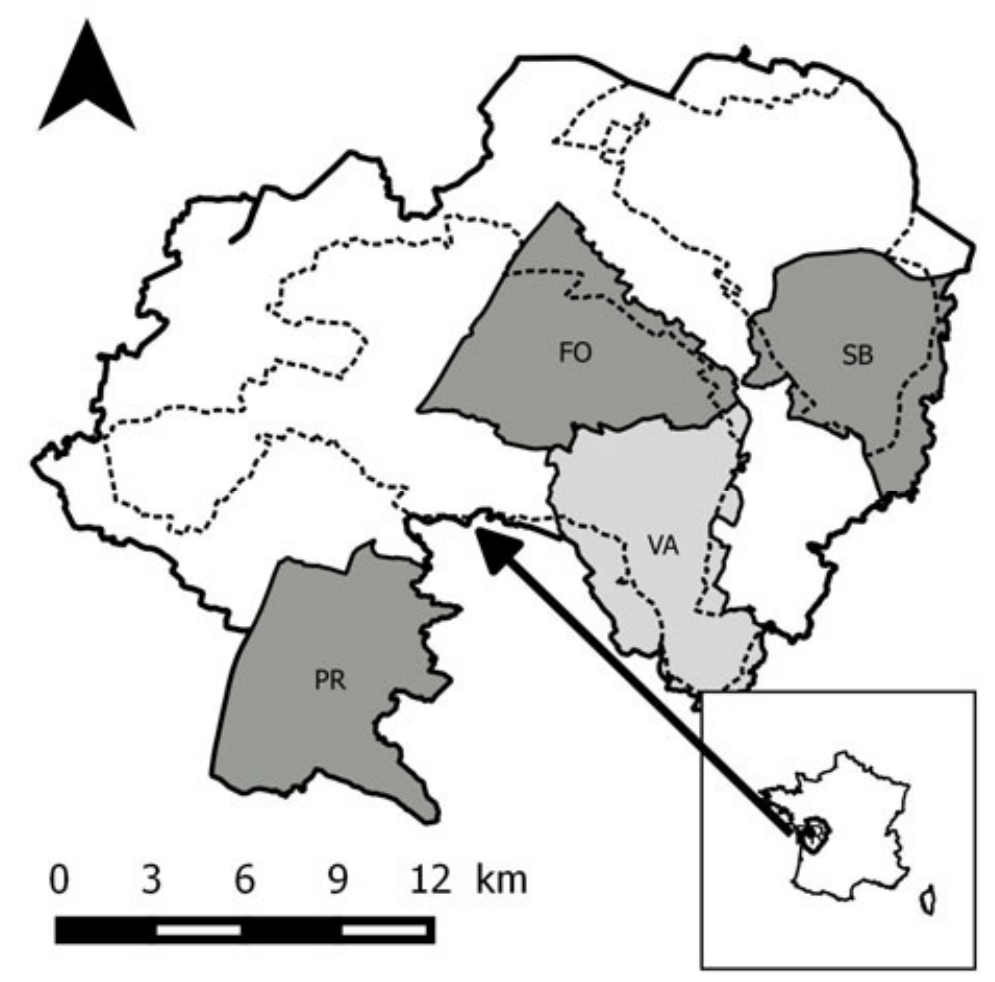

Figure 1. Map of the study area, the Long Term Social-Ecological Research site (LTSER) 'Zone Atelier Plaine \& Val de Sèvre'. The grey polygons correspond to the four sub-sites used for the survey of the Stone-curlew population, of which 'VA' in light grey corresponds to the monitoring sub-site. The dotted lines delimitate the Special Protected Area (SPA Natura2000, FR5412007). 


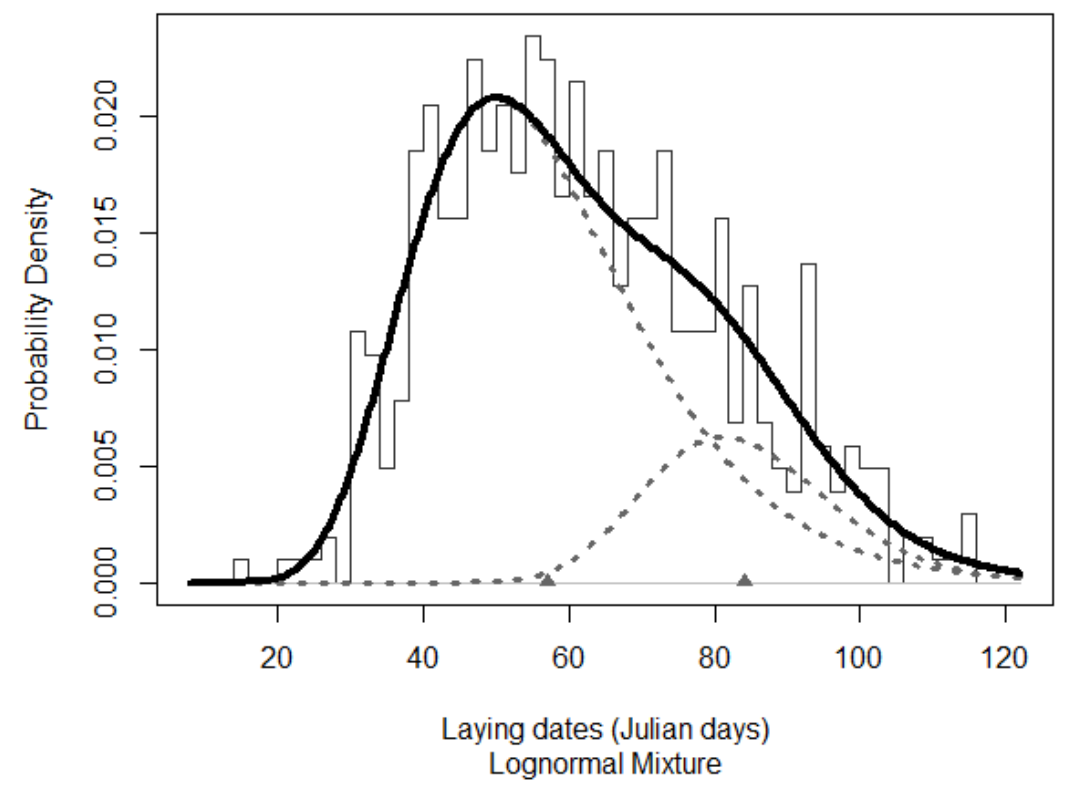

Figure 2. Distribution of laying dates (histogram, $n=513$, 1998-2016), of the fitted lognormal distributions (dotted lines, see Methods) and of the total fitted laying date (thick line). The $x$-axis represent the laying date in Julian days since $1^{\text {st }}$ March $\left(31=1^{\text {st }}\right.$ April, $61=1^{\text {st }}$ May, $92=1^{\text {st }}$ June). The laying peaks are around the $18^{\text {th }}$ of April and the $22^{\text {th }}$ of May, and the medians (triangles on the $\mathrm{x}$-axis) are around the $27^{\text {th }}$ of April and the $25^{\text {th }}$ of May. 

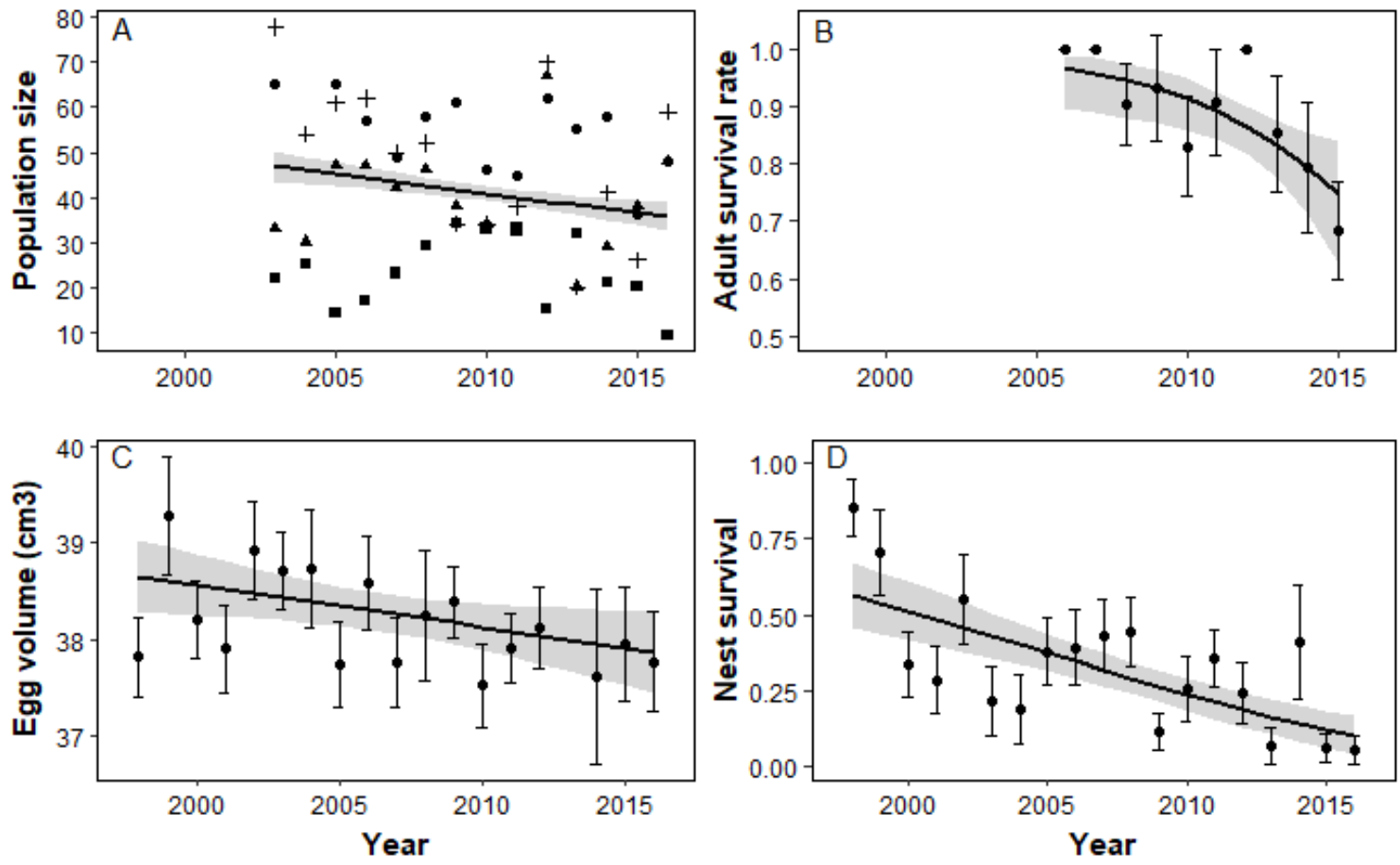

Figure 3. Trends in (A) population size (four sub-sites: cross for VA, triangle for PR, circle for FO and square for SB), (B) adult apparent survival rate \pm se, $(C)$ egg volume \pm se and (D) nest survival \pm se. The predicted values were extracted from the corresponding LM and GLM models (see Methods) and shown with their $95 \% \mathrm{Cl}$. All trends are significant. 


\section{References}

Augiron, S. (2007). Eléments sur la biologie de l'Oedicnème criard en Agro-écosystème intensif et perspective de conservation. Université Paris Sud 11.

Barros, C. \& De Juana, E. 1997. Éxito reproductivo del Alcaraván Burhinus oedicnemus en La Serena (Badajoz, España). Ardeola, 44, 199-206.

Bealey, C.E., Green, R.E., Robson, R, Taylor, C.R. \& Winspear, R. 1999. Factors affecting the numbers and breeding success of Stone Curlews Burhinus oedicnemus at Porton Down, Wiltshire. Bird Study, 46, 145-156.

Glue, D. \& Morgan, R. 1974. Breeding Statistics and Movements of the Stone-curlew. Bird Study, 21, $21-28$.

Green, R.E., Hodson, D.P. \& Holness, P.R. 1997. Survival and movements of Stone Curlews Burhinus oedicnemus ringed in England. Ring. Migr., 18, 24-34.

Powell, L. A. 2007. Approximating variance of demographic parameters using the delta method: a reference for avian biologists. The Condor, 109(4), 949-954.

Solís, J.C. \& Lope, F. 1995. Nest and egg crypsis in the ground-nesting Stone Curlew Burhinus oedicnemus. Journal of Avian Biology, 26, 135-138.

Spena, M.A., Grasso, R., Pollonara, E., Giunchi, D. \& Baldaccini, N.E. 2010. Indagini preliminari sulla biologia riproduttiva e sugli aspetti ecologici dell'Occhione (Burhinus oedicnemus) nella penisola di Thapsos (Siracusa). Biogeographia, 30, 1594-7629.

Vaughan, R. \& Vaughan-Jennings, N. 2005. The Stone Curlew Burhinus oedicnemus. Isabelline Books, Falmouth.Westwood, N.J. 1983. Breeding stone-curlews at Weeting Heath, Norfolk. British Birds, 76, 291-304. 